\title{
Health problems and restrictions of chronic haemodialysis patients
}

\author{
Marta Hreńczuk $^{1 *}$, Weronika Kozieł ${ }^{2}$ and Piotr Małkowski ${ }^{1}$ \\ ${ }^{1}$ Department of Surgical and Transplantation Nursing, and Extracorporeal Treatment, Faculty of Health Sciences, Medical University of Warsaw, Poland \\ ${ }^{2}$ Faculty of Health Sciences, Medical University of Warsaw, Poland
}

\begin{abstract}
Introduction: In Poland, haemodialysis therapy is the dominant renal replacement method, it prolongs life and gives the possibility of waiting for a kidney transplant, however, it is not free from disadvantages.

Purpose: Identification of the health problems of chronic haemodialysis patients.

Material and methods: The study was conducted in a group of 150 patients treated at the Independent Public Central Clinical Hospital at Banacha Street in Warsaw at the Department of General, Vascular and Transplant Surgery and at the Department of Nephrology, Dialysis Therapy and Internal Diseases. A questionnaire of our own design was used to identify the health problems. The analysis was performed using the StatSoft Statistica 13.1 PL statistical suite and the Microsoft Office suite.

Results: $78 \%$ of the respondents accept the treatment method applied to them. Over $50 \%$ of the respondents reported blood pressure fluctuations and general weakness that occur after haemodialysis. Most problems were reported by single individuals ( $<<0.05)$. Haemodialysis patients feel the negative impact of the therapy on their personal, professional, social life and on their mental state.
\end{abstract}

Conclusions: Haemodialysis significantly adversely affects the physical and mental condition of patients. It deteriorates the patients' well-being through troublesome symptoms, inconveniences associated with organizing the procedure and limitations resulting from the therapy.

\section{Introduction}

It is estimated that chronic kidney diseases affect 1 in every 10 persons worldwide [1]. According to the NATPOL 2011 survey, the incidence of chronic kidney disease (CKD) in Poland amounts to $5.8 \%$. Independent risk factors include age, diabetes and hypertension. In addition, due to the ageing population, the incidence of CKD will increase, and thus, the need for hospitalization and renal replacement therapies will also grow. According to approximate data, kidney damage in various stages may be present in up to 4-5 million people in Poland [2]. Meanwhile, the annual incidence of CKD worldwide amounts to approximately $150 /$ million [1,3].

Every disease, as well as the therapy applied in it, affects the daily functioning of a patient. In the case of CKD, in end-stage renal disease, the only possibility of extending a patient's life is the renal replacement therapy. Currently, kidney transplantation is the best method of treating end-stage renal disease and it significantly improves the patients' quality of life. However, the therapy used most commonly in Poland is haemodialysis (HD), which prolongs a patient's life, but is not free from disadvantages. Kidney transplantation has greater benefits in comparison to dialysis, i.e. the elimination of restrictions related to haemodialysis, nutrition or liquid intake, and an almost twice as long life expectancy of patients after transplantation compared to patients on haemodialysis [4-6].

Every year, the number of chronic and long-term haemodialysis patients, treated for a dozen or a few dozen years, increases. It is worth noting that $\mathrm{HD}$ is a renal replacement method, which only helps to rebalance the basic homeostatic disorders, but it does not completely eliminate the consequences of renal failure. Any person treated with haemodialysis, in the absence of contraindications, may be reported as a potential kidney transplant recipient, which is considered to be a better therapeutic solution, which not only extends life but also improves its quality [5-7]. However, according to the Poltransplant data, the average waiting time for the first kidney transplant in 2017, dating from the moment of qualifying and being entered onto The Organ Transplant Waiting List to the day of transplantation, was about 11 months, while when dated from the beginning of dialysis therapy, it was about 1.5 years longer [8].

\section{Purpose}

The purpose of the study was to identify the problems of individuals on haemodialysis, to present the major difficulties and limitations, and to show the largest deficits in meeting the most important needs in the lives, of patients on haemodialysis, and thus, the attempt to identify the needs of an assistance that would improve the functioning of this group.

${ }^{*}$ Correspondence to: Marta Hreńczuk, Department of Surgical and Transplantation Nursing, and Extracorporeal Treatment Ul, Oczki 602-094 Warsaw, Poland, Tel: +48 22 502-19-20; E-mail: marta.hrenczuk@wum.edu.pl

Key words: haemodialysis, chronic kidney disease, health problems

Received: January 21, 2019; Accepted: January 28, 2019; Published: January 31, 2019 


\section{Material and Methods}

The study was conducted from November 2017 to February 2018 at the Dialysis Centre at the Independent Public Central Clinical Hospital at Banacha Street in Warsaw among 150 patients undergoing chronic haemodialysis treatment. The study used the method of a diagnostic survey using a questionnaire of our own design consisting of questions related to health problems and everyday functioning and a scorecard.

The survey was anonymous and the participation was voluntary. Every chronic haemodialysis patient could participate in the study after granting their verbal consent to complete the questionnaire. The study was carried out after obtaining the approval of the Bioethics Committee of the Medical University of Warsaw.

With respect to qualitative data, the results of the research were presented using the quantity and percentage versus the mean quantitative data, standard deviation, median and the minimum and maximum values. In order to check whether statistically significant relationships occur with regard to the variables, an analysis was carried out using the non-parametric Pearson's Chi-Squared test for qualitative data. The distribution of quantitative data was examined using the Shapiro-Wilk Test. After determining the distribution (incompatible with the normal one), the Mann-Whitney $U$ test was used to compare two groups, and the Kruskal-Wallis H Test was used to compare three and more groups. Spearman's correlations were also used to determine the correlations between quantitative data. It was assumed that $\mathrm{p}<0.05$ indicates the presence of a statistically significant correlation. The analysis was performed using the StatSoft Statistica 13.1 PL statistical suite and the Microsoft Office suite.

\section{The socio-demographic status of the respondents}

150 adult responders undergoing chronic haemodialysis treatment participated in the study. Among the respondents, there were 96 women (64\%) and $54(36 \%)$ men. The largest group (41.3\%) consisted of patients aged 46-65. Patients in the age group 31-45 constituted $26.7 \%$, while those over 65 years old - $20 \%$. People under 30 years old were the least numerous group - $12 \% .70 \%$ of the respondents lived in the city, while inhabitants of villages accounted for $30 \% .42 .7 \%$ of the respondents graduated from an upper-secondary school, $28.7 \%$ declared their basic vocational education, and 19.3\% - higher education.
9.3\% of the respondents completed primary school. More than half of the patients were married (52\%), the remaining respondents were unmarried, totalling $48 \%$ (single - $21.4 \%$, divorcé/divorcée - $13.3 \%$ and widower/widow - $13.3 \%)$. The vast majority (78\%) of the respondents lived with their families, $19.3 \%$ lived alone, $2.7 \%$ of them lived in Social Welfare Homes (SWH) or in Care and Treatment Centres (CTC).

$38 \%$ of the respondents were professionally active, pensioners accounted for $26.7 \%$. The unemployed and students accounted for $3.3 \%$ and $5.3 \%$ respectively. For the needs of the analysis, the respondents were regrouped into working and non-working people, they accounted for $38 \%$ and $62 \%$ respectively. $62 \%$ of the respondents evaluated their financial situation to be good, while $38 \%$ said it was bad.

\section{Medical characteristics of the respondents}

Glomerulonephritis (30.7\%), diabetes (30\%) and hypertension (23.3\%) were among the most frequently declared causes that led to renal failure and the need for renal replacement therapy (Figure 1).

The participants indicated the type of vascular access they had, which is the most important element of this therapy. The most respondents $(61.3 \%)$ had an arteriovenous fistula from their own vessels, $11.3 \%$ used an artificial vessel, $14 \%$ had a permanent vascular catheter placed and $13.3 \%$ of them had a temporary vascular catheter. Arteriovenous fistulas from their own vessels were possessed significantly more often by the working respondents (75.4\%) than by non-working ones (pensioners and the unemployed $-52.7 \%$ ), $\mathrm{p}<0.03$. A tendency was observed for arteriovenous fistulas from their own vessels to be possessed more often by women, younger participants, city residents, those in a better material situation, as well as by single and divorced individuals. $22.7 \%$ of the patients were treated with haemodialysis for a period shorter than 1 year, $49.3 \%$ of them between 1 and 5 years, $6 \%$ from 10 to 15 years, $6.7 \%$ of the respondents have been treated for over 15 years. Patients who have undergone dialysis for between one and 5 years, described their financial situation significantly more often as bad (52.6\%) than as good (47.3\%), p<0.008. In addition, people dialysed from one to 5 years were single $(67.7 \%)$ more often than married (42.3\%), $\mathrm{p}<0.0002$. Most respondents (38.6\%) were dialysed during the first $(7.00-13.00)$ shift. The others were dialysed during the second (13.00-19.00) and the third shifts (19.00-24.00), constituting equally $30.7 \%$. For $89.3 \%$ of the patients, the procedures were carried

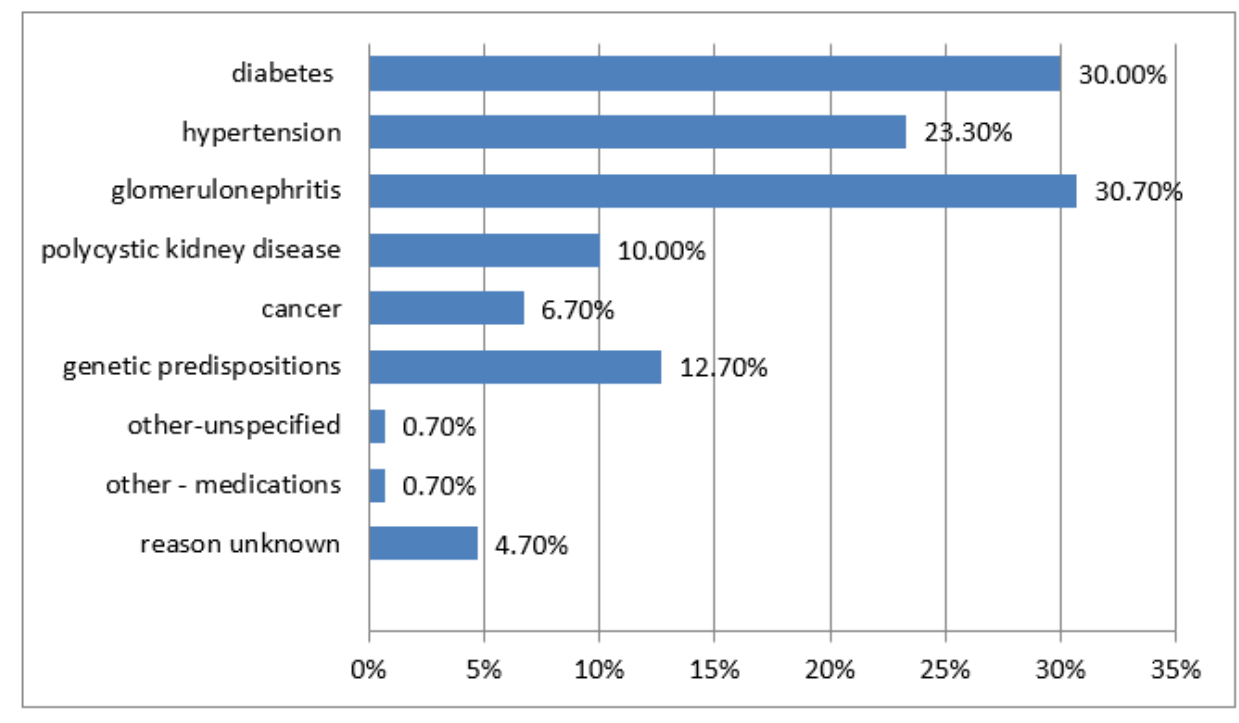

Figure 1. The cause of kidney failure 
out three times a week, and $10 \%$ of them dialysed twice a week. The least numerous group comprised respondents, whose dialysis took place four times a week $(0.7 \%)$. The participants dialysed three times a week were non-working significantly more often (94.6\%) than those professionally active $-80.7 \%, \mathrm{p}<0.01$. In $56.7 \%$ of the respondents, each dialysis lasted 4 to 5 hours. In the case of $42 \%$ of the respondents, a dialysis lasted less than 4 hours, the procedure lasted over 5 hours for $1.3 \%$.

\section{Results}

$55.3 \%$ stated that they were exhausted after haemodialysis. $32.7 \%$ of the respondents described themselves as feeling good. People who assessed their disposition as bad constituted $12 \%$. People who worked reported feeling exhausted significantly more often than non-working people $(61.4 \%$ vs. $51.6 \%), \mathrm{p}<0.05$. The participants whose financial situation was worse, were exhausted after HD significantly more often than those in a good material situation $(70.2 \%$ vs. $46.2 \%), \mathrm{p}<0.02$. Exhaustion after dialysis affected single individuals significantly more often compared to the rest of the group $(\mathrm{p}<0.03)$. A significant portion of the patients have not been hospitalized over the last 6 months $(68.7 \%)$ due to complications related to dialysis, and $31.3 \%$ of the respondents have been hospitalized over the last six months. The fact of hospitalization for people under 30 years old was denied significantly more often than it was confirmed in this age span ( $83.3 \%$ vs. $16.7 \%)$, $\mathrm{p}<0.03$. Also, less affluent individuals denied hospitalizations more often than wealthier ones ( $82.5 \%$ vs. $60.2 \%), \mathrm{p}<0.005$. Hospitalization was denied significantly more often by unmarried people: singles $84.4 \%$ and divorcees $-75 \%$, compared to the rest of the group, $\mathrm{p}<0.05$.

The most frequent bothersome symptoms associated with the therapy indicated by the patients were: general weakness, blood pressure fluctuations, muscle cramps, headaches, itching skin, mental fatigue and insomnia. The respondents experienced: pain in the limb with the arteriovenous fistula, lack of appetite, large body mass gains between dialyses, dyspnoea or constipation significantly less often (Figure 2).
Taking into account the socio-demographic variables, it was the inhabitants of villages who reported blood pressure fluctuations more frequently $(\mathrm{p}<0.02)$. Professionally active patients reported general weakness $(p<0.05)$ and lack of appetite $(p<0.05)$ significantly more often. Meanwhile, non-working people complained about blood pressure fluctuations $(\mathrm{p}<0.006)$, and insomnia $(\mathrm{p}<0.02)$ significantly more often. Single individuals who underwent dialysis indicated symptoms such as itchy skin $(\mathrm{p}<0.03)$, headaches $(\mathrm{p}<0.02)$, general weakness $(\mathrm{p}<0.02)$, insomnia $(\mathrm{p}<0.009)$, pain in the limb with a fistula $(p<0.03)$, excessive weight gains between procedures $(p<0.003)$ and dyspnoea $(p<0.003)$ substantially more frequently. Men reported headaches significantly more often than women $(p<0.05)$; they also affected people under 30 years old more frequently $(\mathrm{p}<0.03)$.

Limitations in the intake of fluids were the fundamental problem indicated by the patients $-69.3 \%$. Men considered this problem to be the biggest inconvenience significantly more often $(p<0.05)$. The study's participants indicated the dialysis ending late and the fatigue associated with it much less frequently - $28 \%$ (significantly more often, it was an inconvenience for people aged $31-45-\mathrm{p}<0.04$ and for working people $\mathrm{p}<0.003$ ), waiting for transport for a long time $-25.3 \%$, getting up early for the dialysis and the sleep deprivation associated with it - $22 \%$ and waiting for a long time to be connected to the machine $8.7 \%$. Getting up early for the dialysis and the sleep deprivation associated with it posed a problem for men significantly more often than for women $(\mathrm{p}<0.05)$. Waiting for transport for a long time was considered significantly more often to be the biggest inconvenience related to dialysis therapy by non-working people $(\mathrm{p}<0.005)$, it was also a significantly more frequent problem of people in a worse financial situation $(\mathrm{p}<0.004)$.

The respondents indicated the appearance of the limb with the arteriovenous fistula (52.7\%) and swelling of the body (51.3\%) as the changes in one's appearance which were the most difficult to accept. Difficulties with moving - $16 \%$, as well as a visible dialysis catheter $14.7 \%$ were a much smaller problem indicated by the respondents.

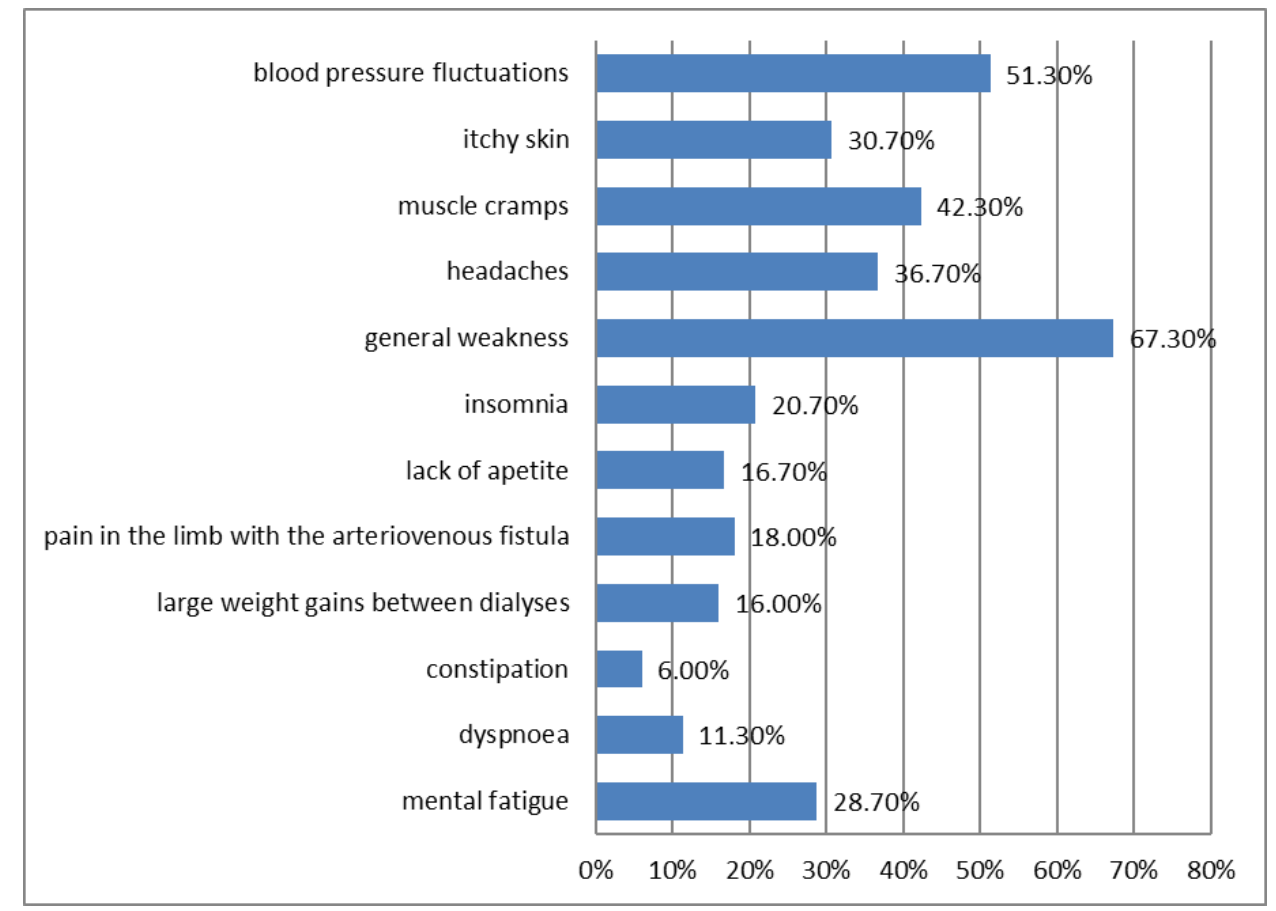

Figure 2. The most frequent bothersome symptoms 
Swelling of the body was difficult to accept for men significantly more often $(\mathrm{p}<0.009)$. The visible dialysis catheter was significantly more often a problem for non-working people than for professionally active ones $(\mathrm{p}<0.04)$. Difficulties with moving were significantly more often reported by people who were over $65(\mathrm{p}<0.002)$, and by those who were unmarried $(\mathrm{p}<0.03)$.

The vast majority of respondents confirmed the influence of dialysis on their professional life $-42.7 \%$. This question did not apply to $42 \%$. Only $4 \%$ of respondents did not have an opinion. People aged 31-45 and under 30 years old reported the effect of the dialysis therapy on their professional life significantly more often than other groups $(\mathrm{p}<0.05)$. HD had an impact on the professional life of the residents of cities significantly more often than in the case of the inhabitants of villages $(\mathrm{p}<0.009)$ and unmarried people $(\mathrm{p}<0.04)$.

The vast majority confirmed the negative effect of the therapy on their everyday life $-83.3 \%$. $2.7 \%$ of the respondents did not have an opinion. The influence of dialysis on daily life was confirmed by men significantly more often $(\mathrm{p}<0.05)$. The remaining analysed variables, namely, the respondents' age, place of residence, being professionally active, financial situation and marital status were not significantly correlated with the influence of dialysis on daily functioning.

$64 \%$ of the respondents confirmed the negative impact of the therapy on their social life. Individuals who indicated that HD has no effect on their social life constituted a smaller percentage - $28 \%$. Only $8 \%$ of respondents had no opinion on this subject. The influence of dialysis on social life was confirmed significantly more often by men $(\mathrm{p}<0.02)$, people living in the city $(\mathrm{p}<0.03)$, professionally active $(\mathrm{p}<0.02)$ and unmarried ones $(\mathrm{p}<0.0002)$.

$78 \%$ of the patients confirmed the negative impact of the therapy on their mental health, for $18 \%$ it had no impact, $4 \%$ of the respondents did not have an opinion on this subject. The influence of haemodialysis on mental health was significantly more often confirmed by men $(p<0.02)$. The remaining variables, namely, the age of the respondents, place of residence, being professionally active, financial situation and marital status were not significantly correlated with the influence of dialysis on mental health.

$78 \%$ of the respondents accept the treatment method applied to them, others do not accept it. Non-working people, including pensioners, retired people, the unemployed, accepted haemodialysis significantly more often than professionally active individuals $(\mathrm{p}<0.03)$. The remaining variables, namely, sex, respondents' age, place of residence, financial situation and marital status were not significantly correlated with the acceptance of dialysis as a treatment method.

\section{Discussion}

Chronic kidney disease is a progressive disorder that leads to permanent kidney damage regardless of sex, age, place of residence, marital status, occupational activity or financial situation. And when one develops it, in the last stage, it is necessary to implement one of the methods of renal replacement therapy: haemodialysis, peritoneal dialysis or kidney transplantation $[3,9,10]$. Among the responders on haemodialysis, the most common cause of dialysis therapy was glomerulonephritis, diabetic kidney disease and hypertension. More than half of them underwent procedures using an arteriovenous fistula from their own vessels, which is described as the best solution. Almost half of the respondents have been dialysed from one to five years, and $1 / 5$ of them consisted of patients who started a dialysis program a year ago; this is a group for which limitations, difficulties and complications were something new that could pose a problem not only in the physical sphere but also a psychological one and a problem with social functioning.

Haemodialysis is the most common form of renal replacement therapy. Unfortunately, it is considered to be bothersome by many patients because, in its course, there occur numerous problems which deteriorate a patient's quality of life. This therapy is also associated with the need to report to treatments 3 times a week, which disturbs the functioning of these patients in all spheres of life, in a sense making them "slaves" of the therapy. And it is to this therapy patients have to adjust their family, social and professional life, often giving up their professional work. Absence at work does not favour keeping it.

According to Książek [11], problems such as muscle cramps affect $5-20 \%$ patients on dialysis, itchy skin $5 \%$, the same number of them complains of headaches. In Rutkowski's study [12], muscle cramps affected $20 \%$ of dialysed patients, and in studies conducted in Bydgoszcz [6], 25\% of patients. Other complaints relating to dialysis therapy reported by patients from Bydgoszcz include: blood pressure fluctuations $(18 \%)$, headaches $(13 \%)$, weakness $(15 \%)$. In our own study, over $50 \%$ of the respondents reported blood pressure fluctuations and general weakness, $41.3 \%$ complained of muscle cramps, $36.7 \%$ reported headaches and $30.7 \%$ skin itching. This is a much larger percentage than in the studies mentioned earlier. Despite the reported problems, $3 / 5$ of the respondents accept this type of treatment. People inactive professionally belonged to this group statistically more often.

Dutkowska, et al. [13] in their studies compared the quality of life of patients on peritoneal dialysis and those who underwent haemodialysis. The study showed that patients on haemodialysis experienced the symptoms of chronic kidney disease and the applied therapy more severely. These included muscle aches and cramps, chest pain, itchy and dry skin, lack of appetite, a decrease in energy and exhaustion, in addition to many more. The unequal severity of the symptoms experienced by patients on peritoneal dialysis and haemodialysis may be the result of an exacerbation of complications associated with haemodialysis. In the above-mentioned study, inconveniences such as: fluid limitations, insufficient ability to perform daily chores, dependence on medical personnel, stress related to the disease, as well as appearance were also most noticeable in patients on haemodialysis. Potential reasons for this are the limiting restrictions related to haemodialysis itself, the frequency of performing it and the need to commute to a dialysis centre/hospital. The problems which were acute and difficult to accept by respondents in our own study included: fluid limitations reported by $69.3 \%$, the appearance of the limb with an arteriovenous fistula for $52.7 \%$ and body swelling for $51.3 \%$. Meanwhile, every second patient felt exhausted after a dialysis session, which is why they probably needed time to rest, which also had an impact on their exclusion from everyday family or social life. These results correlate with the results of the studies by Zielińska - Więczkowska and Krokowska [14], in which the most frequently reported difficulties were fluid limitations (73.4\%), appearance of the limb with a fistula (35.6\%), swelling (11.49\%), and $46.2 \%$ of the patients felt exhausted after a dialysis. It may be supposed that exhaustion and weakness after a dialysis may have been exacerbated by the procedure occurring too late in the day or getting up too early for the procedure (especially for young people aged 31-45) or having to wait for transport for a long time after the procedure (single people). It would be worth considering whether and how to change these reported inconveniences. It seems that with a good organization of the work performed by the teams transporting patients and the dialysis centre, this might be possible 
The main goal of modern medicine is to prolong the life of patients and improve their functioning in everyday life. Currently, the quality of life of chronically ill patients or those undergoing a specific therapy is a very frequent research subject. The quality of life of people with chronic kidney disease is much worse in the physical, mental and social sphere compared to healthy people [15]. On top of that, there is also the nature of the renal replacement therapy, which is burdened with specific negative symptoms or limitations described earlier.

The majority of respondents in our own study pointed to the negative impact of the applied therapy on everyday life, especially men, mental health, significantly more often men, social life, also significantly more often men, residents of cities, professionally active people and single individuals. For $42.7 \%$, the therapy had a negative impact on their professional life, which was indicated significantly more often by people under 45 years old. It should be emphasized that over $1 / 4$ of the patients who participated in our own study were beneficiaries of social pensions. The results of the study conducted show the negative impact of haemodialysis on all spheres of life. Patients on haemodialysis experience a deficit in many areas of their life (physical, social and mental). This is related not only to the disease's symptoms but also to the treatment method applied and its side effects [16].

The symptoms of CKD, the therapy applied and its side effects force the necessity to reduce professional activity among patients on dialysis. Haemodialysis is a form of renal replacement therapy that requires limitations in every aspect of a patient's life. The positive perception of one's quality of life is influenced by professional work, satisfaction and financial independence, as well as self-reliance. Working people are often more motivated to deal with the applied therapy used and to fight against a chronic illness [16,17]. As a result, there arises an important thought about putting more emphasis on psychological support for the patients, about interdisciplinary teams directing patients to support groups for people on dialysis, thanks to which they would get to know their illness better, learn to live with it and perhaps attempt to find activities that would make them happy.

Despite many previous studies, the general observations from our own studies are similar to those conducted previously and it seems that there is still a lack of effective support for patients undergoing haemodialysis. It is still important to emphasize the comfort and quality of life of these patients, and not to only pay attention to the effect of the therapy itself, consisting of extending the lives of patients suffering from chronic kidney disease, who undergo haemodialysis [10,16-19]. Based on determining the deficits, it is worth attempting to improve the daily functioning of this group of patients because one needs to remember that this is still the most frequently used renal replacement therapy method.

\section{Conclusions}

1. The renal replacement therapy that haemodialysis constitutes significantly affects the physical and mental condition of patients in an adverse manner. It deteriorates the well-being of patients through troublesome symptoms, primarily ones such as general weakness, blood pressure fluctuations, muscle cramps, headaches and itchy skin.
2. Haemodialysis has a negative effect, especially on every day and social life, as well as mental health, about which men complained significantly more often.

3. The reporting of side effects, inconveniences and problems related to the therapy was influenced by socio-demographic variables. Most problems were reported by single individuals.

\section{Conflicts of Interest}

The authors declare no conflict of interest.

\section{References}

1. Internal Society of Nephrology (2017) Global kidney health 2017 and beyond: a roadmap for closing gaps in care, research, and policy.

2. Report of the Provincial Consultant in the field of nephrology for 2016.

3. Neuen BL, Chadban SJ, Demaio AR, Johnson DW, Perkovic V (2017) Chronic kidney disease and the global NCDs agenda. BMJ Glob Health 2: e000380. [Crossref]

4. Getek M, Czech N, Białek-Dratwa A (2012) Quality of life in patients subjected to chronic renal replacement therapy - literature review. Hygeia Public Health 47: 151156

5. Bojanowska M, Hreńczuk M, Jonas M (2015) Treatment with hemodialysis and kidney transplantation in the opinion of patients waiting for transplantation. Polish Nursing 3: $278-282$.

6. Gętek M, Nowakowska-Zajdel E, Czech N (2010) Quality of life in hemodialysis, peritoneal dialysis, and transplantation patients. Ann Acad Med Siles 64: 23-30.

7. Kochan-Wójcik M, Prokopowicz K (2015) Psychological help for hemodialysis patients - example of cooperation between the university and the dialysis station. Forum Nefrologiczne 8: 122-129.

8. http://poltransplant.pl/Download/Biuletyn_2018.pdf

9. Johns TS, Yee J, Smith-Jules T (2015) Interdisciplinary care clinics in chronic kidney disease. BMC Nephrol 16: 161-171. [Crossref]

10. Rutkowski B, Czekalski S (2001) Standards of conduct in the diagnosis and treatment of kidney diseases.

11. Książek A (2003) Podręcznik dializoterapii. Wydawnictwo Czelej, Lublin.

12. Rutkowski B, Czekalski S (2008) Rozpoznawanie i leczenie chorób nerek - wytyczne, zalecenia i standardy postępowania. Wydawnictwo Medyczne TerMedia, Poznań.

13. Dutkowska D, Rumianowski B, Grochans E (2012) Comparison of the life quality of hemodialysis and peritoneal patients. Problemy Higieny $i$ Epidemiologii 93: 529-535.

14. Zielińska-Więczkowska H, Krokowska B (2014) Assessment of life quality in dialysis patients. Medycyna Rodzinna 2: 42-45.

15. Hornik B, Kempny-Kwoka D, Włodarczyk-Sporek I (2014) Quality of life in hemodialysis, peritoneal dialysis, and transplantation patients. Zdrowie i Dobrostan 2: 65-78.

16. Wnuk M, Zielonka D, Purandare B (2013) Review of the quality of life conceptions in social sciences. Hygeia Public Health 48: 10-16.

17. Zhou X, Xue F, Wang H, Qiao Y, Liu G (2017) The quality of life and associated factors in patients on maintenance hemodialysis - a multicenter study in Shanxi province. Ren Fail 39: 707-711. [Crossref]

18. Ju A, Unruh ML, Davison SN, Dapueto J, Dew MA (2017) Patient-Reported Outcome Measures for Fatigue in Patients on Hemodialysis: A systematic Review. Am J Kidney Dis 71: 327-343. [Crossref]

19. Sathivik BS, Parthasarathi G, Narahari MG, Gurudev KC (2008) An assessment of the Quality of life in hemodialysis patients using the WHOQOL-Bref questionnaire. Indian J Nephrol 18: 141-149. [Crossref]

Copyright: (2019 Hreńczuk M. This is an open-access article distributed under the terms of the Creative Commons Attribution License, which permits unrestricted use, distribution, and reproduction in any medium, provided the original author and source are credited. 